\section{BOOK REVIEWS}

Life-style and Mortality: a Large-scale Census-based Cohort Study in Japan. Hirayama T. (Pp 138; £84.80.) Karger, Basel, 1990. (No 6 in Contributions to Epidemiology and Biostatistics, Series Editor Wahrendorf J.) ISBN 3-8055-5201-7.

This series on "Contributions to Epidemiology and Biostatistics" provides space for researchers responsible for large studies to present their material in more detail than is usually permitted in original publications in scientific journals.

Dr Hirayama brings together in this volume his work on life style and mortality over the past 25 years, using data collected in a census based cohort study following up some 270000 adults for 17 years. He provides a detailed description of the origins and design of the study, and the main findingsmost of which have previously been published. This is a typical example of the large scale epidemiological studies which the editors of the series had in mind when the series was started in 1979

The study grew out of the two large cohort studies on the effects of cigarette smoking which were started in the early 1950s in the UK by Doll and Hill and the USA by the American Cancer Society. Dr Hirayama, guided by Dr Cuyler Hammond and Sir Richard Doll, selected six prefectures in Japan, conducted two censuses of people living in those prefectures in 1965 and in 1971 (a 3\% sub-sample), and followed up all people over 40 years of age who remained in those prefectures over the period 1966-82.

The use of very simple questionnairesadministered by health nurses and midwives on home visits-has provided a rich data bank which has contributed significantly to discussions about relationships between smoking and mortality; alcohol and mortality; diet and mortality; marital status, reproductive history and mortality; and occupation, socioeconomic status and mortality.

Without doubt, the most influential contributions from this study have come from the important data on relationships between cigarette consumption (active and passive smoking) and a variety of different causes of death. The size of the study, the representativeness of the population followed, the detailed smoking data, and the success of follow up all combined to make this a uniquely powerful source for addressing major public health questions.

The publishers are to be congratulated for having invited Dr Hirayama to prepare this volume. His systematic and tidy presentation provides the reader, in relatively short space, with a clear guide through the main activities of maintaining and analysing a study on this scale. It is partly a result of the obvious success of early studies such as this that there are now a number of similar studies across the world using a variety of different follow up methods. This book, while expensive, will be of interest to the growing number of researchers who are planning or running similar studies.

JOHN FOX

Office of Population Censuses \& Surveys London

Biological Markers in Epidemiology. Hulka B S, Wilcosky T C, Griffith J. (Pp 236; £32.00.) Oxford, Oxford University Press, 1990. ISBN 019-5059840.

This book sets out to explain the current status and future potential of molecular epidemiology as a field of scientific inquiry In this aim it succeeds admirably, and provides an excellent introductory overview on the subject. Although the chapters are written by different authors, the whole book has been put together with great care and attention to detail. There is little unnecessary repetition, good overlap of information, and a clear flow and direction of the developing themes. The techniques and concepts discussed are presented in adequate detail for any basic scientist to grasp, and each chapter contains a clear summary of the major points, and a number of references for further reading.

The book starts with three chapters giving an overview of the types of biomarkers available, the rationale for their use, and their constraints in epidemiological research. The criteria for selecting and evaluating differen markers is then discussed, with examples of problems that can be addressed. The next five chapters describe different tests in detail including urine mutagenicity assays, protein and DNA adducts, sister chromatid exchange, analysis of micronuclei in differen cells, and detection of chromosome aberrations, such as breakage and fragmentation. After a basic description of each of these tests, examples of their application in the study of different diseases are given, together with the pitfalls and advantages of the tests relative to each other. For some of the tests, comparisons are also made as to the relative cost of developing and carrying them out, which is an important factor in this day and age. The ethical issues raised by the finding of abnormalities using these tests are discussed briefly, though not covered in great detail.

One of the important areas of future research is the use of biological markers in the study of cancer susceptibility, and the largest chapter deals with oncogenes and the use of DNA techniques for their study. An overview is given about the discovery of oncogenes, the mechanism of their formation and their function, together with a basic description of recombinant DNA technology. The reader is taken through all these with great speed, and non-experts may need to refer to some of the recommended papers for further reading. This chapter recognises that the contribution to the field of cancer epidemiology using these approaches is much less extensive than would be expected for the amount of discussion that the topic has generated, but suggests how the use of biological markers in future research should demonstrate their usefulness as an epidemiological tool.
The final chapters investigate the application of biological markers to the study of susceptibility to diseases such as cancer, and the book ends with a review of methodological issues such as the choice of a marker, its stability, particularly in the face of biological variability, and the problems of sample size and confounding factors. The authors conclude that "biological markers will play a prominent role in epidemiologic research of the 1990s" and this book will serve as an extremely useful basis for those investigators who want to include such markers in their future research efforts.

\section{$S$ HUMPHRIES \\ The Charing Cross Sunley Research Centre Hammersmith London}

The Challenges of Medical Practice Variations. Eds T F Andersen, G Mooney. (Pp 200; £14.95) London, Macmillan, 1990 ISBN 0-333-47509-7.

As costs of health care have risen inexorably, increasingly searching questions have been asked about its benefits to society relative to those which might accrue from alternative uses of scarce resources. Attempts have been made to clarify the objectives of health care, to control expenditure, and to call health professionals to account for the resources they commit. Particular attention has been focused on the behaviour of doctors, whose decisions are so important. Research has revealed variations in practice which remain largely unexplained. This book asserts that the variations are evidence that "medical practice floats on a sea of uncertainty".

The 14 expert contributors have amassed impressive material which is up to date and well referenced. There is guidance about research methods and a description of studies by the Health Services Commission in Manitoba which maintains a longitudinal database of its population's use of health care. There are interesting accounts of the implications of practice variation for equity in health care; the use of interactive video disk technology and decision analysis to assist patients to choose between alternative treatments for benign prostatism; and strategies to contain the increasing use of caesarean sections. The authors assert that doctors must be seen to be questioning unexplained variations in practice if they are to avoid external regulation. The challenges for policy makers are to make explicit priorities and goals of health care and to provide the right incentives to ensure that all players in the delivery of health care pursue efficiency.

The book will be of interest to public health physicians, to health care researchers, to health economists, to managers, and to analysts of social policy. I suspect that its contents will prove increasingly relevant as the National Health Service develops health care contracts between purchasers and providers. 